$\S=-1$

\title{
Optimisation of SC-CO 2 Extraction of Curcuma zedoaria by Response Surface Methodology
}

\author{
Istikamah Subuki ${ }^{1 *}$, Saidatul H. Saidin ${ }^{2}$, Nurul Nabilah M. Hisan ${ }^{1}$ \\ ${ }^{I}$ Faculty of Chemical Engineering, Universiti Teknologi MARA, Shah Alam, 40450, Selangor, Malaysia \\ ${ }^{2}$ Department of Produk Pembangunan Herba (PPH), Forest Research Institute Malaysia, Kepong, 52109, Kuala Lumpur, Malaysia \\ *Corresponding author E-mail:istikamah@salam.uitm.edu.my
}

\begin{abstract}
In this study, Curcuma zedoaria was extracted using supercritical fluid extraction system (SFE) to obtain valuable extract. Optimisation of extraction condition for high yield and curzerene concentration was carried out by employing the Response Surface Methodology (RSM) particularly, Central Composite Design (CCD). The objectives of this work are to investigate the effect of temperature $\left(40^{\circ} \mathrm{C}\right.$ to $60^{\circ} \mathrm{C}$ ) and pressure (100 to $300 \mathrm{bar}$ ) on extraction yield and concentration of major chemical constituents and determine the optimum parameter for high oil yield and curzerene concentration using RSM. Chemical constituents of the oil were analysed using gas chromatography (GC) and Gas Chromatography Spectrometry (GCMS) and showed that curzerene as the key chemical constituent in the oil extract. The results demonstrated that the oil yield obtained were ranged from $0.6 \mathrm{w} / \mathrm{w} \%$ to $1.8 \mathrm{w} / \mathrm{w} \%$ and curzerene concentration in range of $1.6 \%$ to $4.1 \%$. The optimum parameters predicted by RSM for the highest oil yield and curzerene concentration were found to be 138.65 bar and $40^{\circ} \mathrm{C}$, which produced the best oil yield and curzerene concentration predicted as $1.7 \mathrm{w} / \mathrm{w} \%$ and $3.7 \%$ respectively. In conclusion, the pressure and temperature significantly influence the oil yield and oil concentration as $p \leq 0.05$ for both factor.
\end{abstract}

Keywords: Curcuma zedoaria; Curzerene; Oil yield; RSM; SFE;

\section{Introduction}

Curcuma zedoaria (Berg.) Rosc. (Zingiberaceae) oil can be obtained using either conventional or novel extraction method. Hydrodistillation is one of the conventional methods while supercritical fluid extraction (SFE) is a novel extraction method. The oil obtained using conventional method has been recognised as the most favourable for many decades among researchers. However, the conventional oil extraction methods require long processing time and consume relatively large amounts of organic solvent. Ouzzar et.al (1995) conducted an extraction of natural plant using conventional method almost 5 hours and concluded that some solvent residue remained in the products at the end of the processes. Furthermore, the elevated temperature set during the hydrodistillation process degraded the extracts quality as the temperature triggered chemical modifications to the oil component and this led to the loss of valuable volatile components.

In contrast, SFE has been recognized as safe and fast technique to produce high-quality oil with solvent-free products. In SFE technique, carbon dioxide $\left(\mathrm{CO}_{2}\right)$ is the most popular and common solvent used due to its environmentally friendly properties such as non-toxic, non-flammable, odourless and inert. SFE is an efficient extraction process compared to conventional extraction method because of its high rate of extraction and the solvating power. Shih et.al (2015) conducted SFE of C. zedoaria rhizome within two hours and found that the extracted yield was slightly higher compared to the hydrodistillation. The oil yields acquired by SFE were $0.82 \%$ and $0.99 \%$ while for hydrodistillation, it was $0.63 \%$. Higher throughput of SFE is often defined by the solubility maxima of solutes in a critical fluid (Ozkal, 2004) and thus contributes to the higher yield. The solubility of the solute in a supercritical fluid depends on several factors such as solvent density, solute volatility (vapour pressure) as well as polarity. The increase in solvent density depends on temperature and pressure and it also increases the solubility. Meanwhile, higher solute volatility means high vapour pressure which makes it easier to remove the solute. The increase in vapour pressure leads to an increase in solubility.

For this case, supercritical fluid extraction is used as a technique for $C$. zedoaria extraction. In SFE, the operating parameters were expected to give different effects on the extraction yield and oil component properties. Hence, optimum parameters for the SFE application are essential. The optimum parameter can be determined using Response Surface Methodology (RSM) method. The RSM is an empirical statistical design of experiment method that aims to find the optimum parameters and achieve the best response. RSM also helps to reduce the number of the required experimental trials and reveal the relationship between independent variables towards the responses using multiple regression. In this work, the parameters used including pressure and temperature meanwhile the responses are the extracts oil (oil yield) and curzerene concentration.

The objectives of this study are to investigate the effect of pressure and temperature on the oil yield and curzerene concentration and to determine the optimum parameter of pressure and temperature to obtain high oil yield and curzerene concentration using RSM. The ranges of temperature and pressure used were between 100 bar to 300 bar, and $40^{\circ} \mathrm{C}$ to $60^{\circ} \mathrm{C}$ respectively. Besides, the major chemical constituents in $\mathrm{SC}-\mathrm{CO}_{2} C$. zedoaria extracts was identified via GC and GCMS. 


\section{Methodology}

\subsection{Materials}

Dried C. zedoaria was purchased from Kuala Krau, Pahang. The rhizomes were washed, oven dried and pulverised until their diameter size was within 1 to $3 \mathrm{~mm}$. The moisture content of dried rhizome was $6.28 \%$ on a dry basis. All chemicals and solvents used were of analytical grade. Carbon dioxide $\left(\mathrm{CO}_{2}\right)$ with $99.9 \%$ purity, dichloromethane (DCM) with $99.9 \%$ purity and helium with $99 \%$ purity were used in this experiment.

\subsection{Experimental Apparatus and Procedure}

Supercritical $\mathrm{CO}_{2}\left(\mathrm{SC}-\mathrm{CO}_{2}\right)$ extraction of $C$. zedoaria was performed using a laboratory scale supercritical-fluid extraction system (SFE 500MR, Thar Technology). The ranges of pressure and temperature used were $100-300 \mathrm{bar}$ and $40^{\circ} \mathrm{C}-60^{\circ} \mathrm{C}$ respectively. About $200 \mathrm{~g}$ ground dried C. zedoaria was placed in the 1000 $\mathrm{ml}$ extraction vessel. After the recirculating chiller reached $3^{\circ} \mathrm{C}$, $\mathrm{CO}_{2}$ was supplied continuously from the gas cylinder into the extractor at a fixed flow rate of $35 \mathrm{~g} / \mathrm{min}$. The gas $\mathrm{CO}_{2}$ was cooled using a cooling heat exchanger and liquefied into denser $\mathrm{CO}_{2}$. The liquefied $\mathrm{CO}_{2}$ was then pressurised by pumping the $\mathrm{CO}_{2}$ to the desired pressure and heated to a specific temperature with the purpose of reaching the supercritical state. The extraction process was carried out in 30 minutes for static and 1 hour for dynamic extraction time. The pressure within the extraction vessel was regulated by an automated back pressure regulator (ABPR) while manual back pressure regulator (MBPR) maintained the pressure in the collector constant. After the extraction process, the pressure in extraction vessel was depressurised by ABPR and the extracted oil yield was collected through the drain valve. The $C$. zedoaria extract oil yield was calculated using Eq. (1).

Yield $(\%)=\left[\mathrm{M}_{\text {extract }}(\mathrm{g}) / \mathrm{M}_{\text {feed }}(\mathrm{g})\right] \times 100$

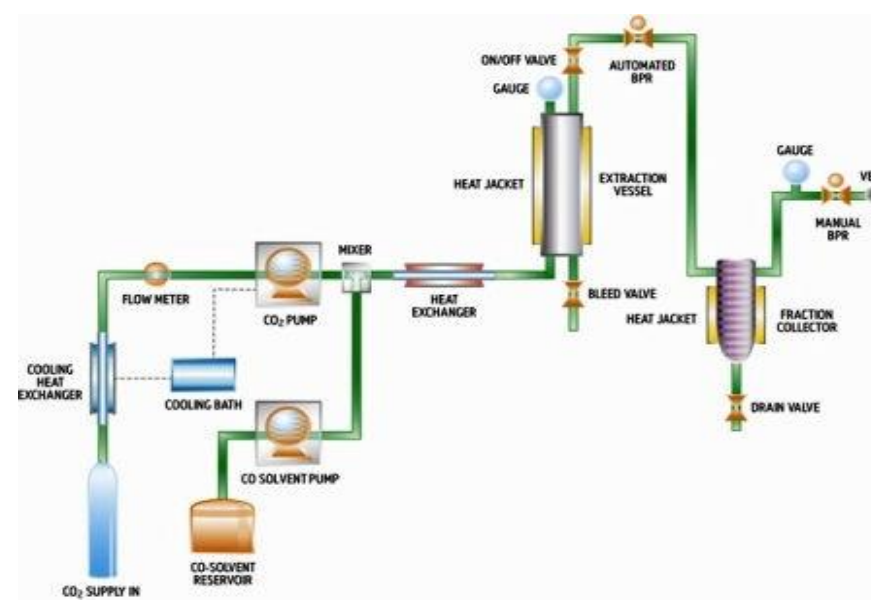

\subsection{Experimental Design}

The SC- $\mathrm{CO}_{2}$ extraction parameters were optimised by employing the Response Surface Response (RSM). In the RSM, the relationship between independent variables (pressure and temperature) towards the responses oil yield was investigated. 13 experiments including 4 factorial points, 4 axial points and 5 central points were assigned based on the Central Composite Design (CCD). By using Expert Design version 7.0 software, the contrasting coefficients among the obtained experimental data were well tuned and statistically analysed using Analysis of Variance (Manickam et.al, 2012). The mathematical models for each response were predicted by using multiple regression models and were fitted into second order polynomial Eq. (2).
$\mathrm{Y}=\beta_{\mathrm{o}}+\Sigma \beta_{\mathrm{i}} \mathrm{X}_{\mathrm{i}}+\beta_{\mathrm{ii}} \mathrm{X}_{\mathrm{i}}^{2}+\Sigma \Sigma \beta_{\mathrm{ij}} \mathrm{X}_{\mathrm{i}} \mathrm{X}_{\mathrm{j}}$

Where $\mathrm{Y}$ is the response variable, $\beta_{\mathrm{o}}$ is a constant, and $\beta_{\mathrm{i}}, \beta_{\mathrm{ii}}$, and $\beta_{\mathrm{ij}}$ represents the linear, quadratic and interactive coefficients respectively. $X_{i}$ and $X_{j}$ are the independent variables. The coefficient of determination, $\mathrm{R}^{2}$ was determined and the F-test of significance of the equation parameters for each response variable was analysed. According to Paulucci et.al, only the factors with significance higher than or equal to $5 \%(p \leq 0.05)$ were considered.

\subsection{GC and GCMS Analysis}

The chemical analysis composition of extracts was analysed via gas chromatography (GC) equipped with a DB Wax column (30 m x $0.5 \mathrm{~mm}$ i.d, film thickness $0.25 \mu \mathrm{m}$ ). The detectors used were Mass Spectrometer Detector (MSD) and Flame Ionisation Detector (FID). The carrier gas used was helium at pressure $210 \mathrm{kPa}$ and the temperature of the injector as well as the detector were set to $240^{\circ} \mathrm{C}$. The oven's temperature was initially set at $60{ }^{\circ} \mathrm{C}$ for 1 minute and then the heating process was programmed from 60 to $240^{\circ} \mathrm{C}$ at the rate of $5{ }^{\circ} \mathrm{C} / \mathrm{min}$ and finally remained at $240^{\circ} \mathrm{C}$ for another minute. $1 \mu \mathrm{l}$ of the sample was injected and the split ratio was 1:20.

\section{Result and Discussion}

\subsection{SFE of Curcuma Zedoaria Rhizome}

The results of the oil yields of SC- $\mathrm{CO}_{2}$ of C. zedoaria were presented in Table 1.1. Results showed that extraction yield of the oil were from $0.6 \mathrm{w} / \mathrm{w} \%$ to $1.8 \mathrm{w} / \mathrm{w} \%$ for pressure ranging from 100 to $300 \mathrm{bar}$ and $40^{\circ} \mathrm{C}$ to $60^{\circ} \mathrm{C}$. These results agree with the assertion that most extraction of medicinal plants will yield less than $5 \%$. A previous study on Curcuma showed that the yield of essential oil obtained from both fresh and dried rhizomes of turmeric ranged from $0.7 \%$ to $1.1 \%$ (Hong et.al, 2014). Awasthi et.al claimed that the oils obtained by conventional hydrodistillation of the rhizomes and leaves of $C$. longa were $0.36 \%$ and $0.53 \%$ respectively. Thus, it can be concluded that the oil yield percentage obtained was somewhat similar to the trend of related studies even though different parameters and extraction method were used. In addition, a recent Chinese report showed that the zedoary oil can be formulated as a submicron emulsion. According to the report, a $2.0 \mathrm{~g}$ of zedoary oil was required in the formula and this value proved that the oil yield obtained from the experiment was able to meet the pharmaceutical requirement (Zhihui et.al, 2014).

Table 1.1: The weight of oil from SFE of Curcuma zedoaria dried rhizome according to the following parameter.

\begin{tabular}{|c|c|c|c|c|}
\hline \multirow[t]{2}{*}{ Run } & \multicolumn{2}{|c|}{ Factors } & \multirow{2}{*}{$\begin{array}{c}\text { Wt of } \\
\text { oil yield } \\
\text { (g) }\end{array}$} & \multirow{2}{*}{$\begin{array}{c}\text { Oil } \\
\text { yield } \\
(w / w \%)\end{array}$} \\
\hline & $\begin{array}{c}A= \\
\text { (bar) }\end{array}$ & $\begin{array}{c}\mathbf{B}=\text { Temperature } \\
\left({ }^{\circ} \mathrm{C}\right)\end{array}$ & & \\
\hline SFE 1 & 100 & 50 & 1.54 & 0.769 \\
\hline SFE 2 & 200 & 50 & 3.22 & 1.612 \\
\hline SFE 3 & 100 & 60 & 1.22 & 0.609 \\
\hline SFE 4 & 200 & 50 & 3.14 & 1.57 \\
\hline SFE 5 & 300 & 50 & 3.18 & 1.589 \\
\hline SFE 6 & 300 & 40 & 2.83 & 1.414 \\
\hline SFE 7 & 300 & 60 & 3.21 & 1.604 \\
\hline SFE 8 & 100 & 40 & 3.31 & 1.654 \\
\hline SFE 9 & 200 & 50 & 3.18 & 1.593 \\
\hline SFE 10 & 200 & 50 & 3.18 & 1.592 \\
\hline SFE 11 & 200 & 40 & 3 & 1.499 \\
\hline SFE 12 & 200 & 50 & 3.24 & 1.62 \\
\hline SFE 13 & 200 & 60 & 3.74 & 1.869 \\
\hline
\end{tabular}

\subsection{Chemical Investigation}

Based on the GC and GCMS analysis, results revealed that more than 30 constituents were identified in the extracted oil. The oil 
mainly contained sesquiterpene and mono sesquiterpene hydrocarbons (terpenes). This behaviour is coincided to the finding of Shih et.al (2015) that the essential oil of $C$. zedoaria extracted by SFE contained a high ratio of terpenes constituents. Among 30 constituents, curzerene was found as the desired major constituent. SFE 8 (temperature $40^{\circ} \mathrm{C}$, pressure 100 bar) gave the highest percentage concentration of curzerene $(4.07 \%)$ while the lowest percentage concentration was from SFE 3 (temperature $60^{\circ} \mathrm{C}$, pressure 100 bar) with $1.58 \%$. The results of the major constituents in oil C. zedoaria agree to those reported by Angel et.al (2014) in which cuzerene $(8 \%)$ and epicurzerenone $(19 \%)$ were the major compounds in the essential oil of $C$. zedoaria from Kerala, India. In addition, Richard, Kirti, and Annie (2009) conveyed that curzerenone $(22.3 \%), 1,8$ cineole $(15.9 \%)$ and germacrone $(9 \%)$ as the major compounds of the essential oil whereas Mau et al (2003) had identified curzerene $(10.36 \%)$, epicurzerenone $(24.08 \%)$, isocurcumenol (2.98\%), 5-isopropylidene-3,7,dimethyl-1 (5H)-azulnone (4.3\%) and curdione (7\%).

Table 1.2: Major compound of oil extracted of Curcuma zedoaria

\begin{tabular}{|c|c|c|c|c|}
\hline \multirow{2}{*}{ Run } & $\begin{array}{c}\text { Total identi- } \\
\text { fied constitu- } \\
\text { ents }\end{array}$ & $\begin{array}{c}\text { Concentration } \\
(\boldsymbol{\%})\end{array}$ & KI & Identification \\
\hline SFE 1 & 33 & 3.158 & 1851 & MS, RI \\
\hline SFE 2 & 34 & 2.75 & 1852 & MS, RI \\
\hline SFE 3 & 33 & 1.579 & 1851 & MS, RI \\
\hline SFE 4 & 34 & 2.89 & 1852 & MS, RI \\
\hline SFE 5 & 34 & 2.06 & 1852 & MS, RI \\
\hline SFE 6 & 34 & 2.199 & 1852 & MS, RI \\
\hline SFE 7 & 34 & 2.326 & 1851 & MS, RI \\
\hline SFE 8 & 34 & 4.073 & 1854 & MS, RI \\
\hline SFE 9 & 34 & 2.92 & 1852 & MS, RI \\
\hline SFE 10 & 34 & 2.913 & 1852 & MS, RI \\
\hline SFE 11 & 39 & 2.818 & 1852 & MS, RI \\
\hline SFE 12 & 34 & 2.97 & 1852 & MS, RI \\
\hline SFE 13 & 35 & 2.196 & 1852 & MS, RI \\
\hline
\end{tabular}

\subsection{Response Surface Methodology}

The Response Surface Methodology (RSM) was used to determine the optimum variables with the best responses. In this case, the oil yield and curzerene concentration were the responses while pressure and temperature were two independent variables. The relationship between two independent variables and response have been analysed by RSM to obtain the predicted of both responses. Table 1.3 shows the Central Composite Design (CCD) matrix of experimental and predicted of oil yield and curzerene concentration based on the independent variables (pressure and temperature). A quadratic model was suggested since CCD can fit a full quadratic model.

Table 1.3: The independent variables for extraction of Curcuma zedoaria along with experimental and predicted values of oil yield and curzerene concentration

\begin{tabular}{|c|c|c|c|c|}
\hline \multirow{2}{*}{ Run } & \multicolumn{2}{|c|}{ Oil yield \% } & \multicolumn{2}{c|}{ Curzerene concentration } \\
\cline { 2 - 5 } & $\begin{array}{c}\text { Experimen } \\
\text { tal }\end{array}$ & Predicted & Experimental & Predicted \\
\hline SFE 1 & 0.769 & 0.935 & 3.158 & 3.089 \\
\hline SFE 2 & 1.612 & 1.589 & 2.75 & 2.845 \\
\hline SFE 3 & 0.609 & 0.658 & 1.579 & 1.707 \\
\hline SFE 4 & 1.57 & 1.589 & 2.89 & 2.845 \\
\hline SFE 5 & 1.589 & 1.460 & 2.06 & 2.347 \\
\hline SFE 6 & 1.414 & 1.345 & 2.199 & 1.962 \\
\hline SFE 7 & 1.604 & 1.801 & 2.326 & 2.276 \\
\hline SFE 8 & 1.654 & 1.437 & 4.073 & 4.014 \\
\hline SFE 9 & 1.593 & 1.589 & 2.92 & 2.845 \\
\hline SFE 10 & 1.592 & 1.589 & 2.913 & 2.845 \\
\hline SFE 11 & 1.499 & 1.783 & 2.818 & 3.114 \\
\hline SFE 12 & 1.62 & 1.589 & 2.97 & 2.845 \\
\hline SFE 13 & 1.869 & 1.62211 & 2.196 & 2.118 \\
\hline
\end{tabular}

The Analysis of Variance (ANOVA) was performed so that the goodness of the fit can be evaluated. The ANOVA predicted the values for oil yield and curzerene concentration calculated using regression model and compared with experimental values obtained from the experiment. Figure 1.1 and 1.2 show the correlation between experimental and predicted values of oil yield and curzerene concentration. Both response variables were fitted into a second order polynomial equation presented in Eq. (3) and (4) respectively. Based on Figures 1.1 and 1.2, the experimental responses were closer to the predicted responses as most of the point concentrated around the 45-degree line.

Oil yield $\%=$

$0.91-0.07 \mathrm{~A}+0.069 \mathrm{~B}+0.11 \mathrm{AB}-0.27 \mathrm{~A}^{2}-0.19 \mathrm{~B}^{2}$

Curzerene concentration $\%=$

$2.84-0.37 \mathrm{~A}-0.5 \mathrm{~B}+0.66 \mathrm{AB}-0.13 \mathrm{~A}^{2}-0.23 \mathrm{~B}^{2}$

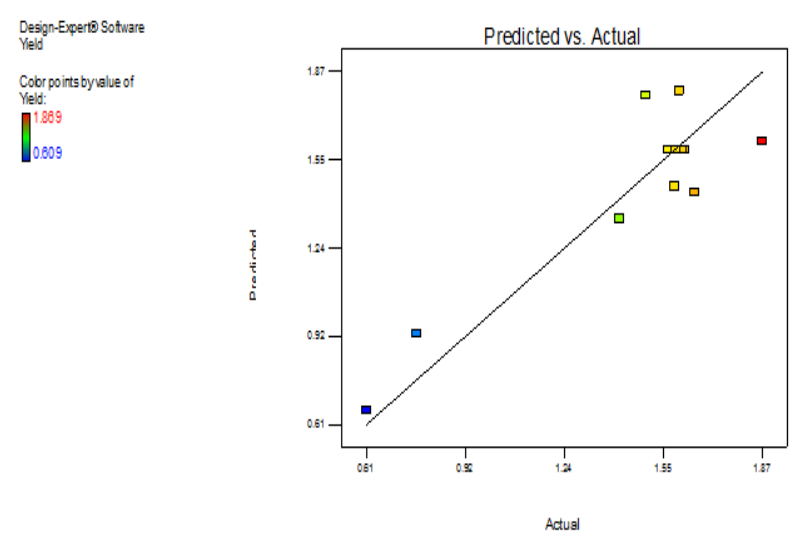

Fig. 1.1: Relationship between experimental and predicted values of oil yield
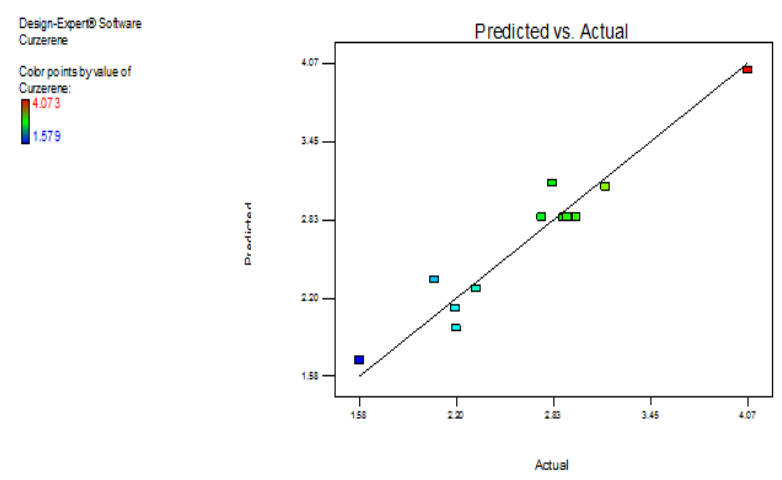

Fig.1.2: Relationship between experimental and predicted value of the curzerene concentration

According to Azmir et.al (2014), the coefficient of determination $\left(\mathrm{R}^{2}\right)$ of the model of 0.99 indicated a similarity between the experimental and predicted response variables. Meanwhile, Siti et.al (2015) stated that the $\mathrm{R}^{2}$ value for all response variables that were higher than 0.75 implying that the regression model capable of presenting the response well. The $\mathrm{R}^{2}$ value of oil yield and curzerene concentration were 0.8180 and 0.9357 respectively. Therefore, it can be concluded that the regression model can explained the response well with a good fit.

Table 1.4 shows that the quadratic term of pressure $\left(\mathrm{A}^{2}\right)$ and linear pressure (A) effects were highly significant $(p \leq 0.05)$. However, linear temperature (B) and quadratic term of temperature $\left(\mathrm{B}^{2}\right)$ effects give $p \geq 0.05$ which is non-significant. The interaction between temperature (B) and pressure (A) was significant ( $p \leq$ 0.05 ) within the experimental ranges. The ANOVA regression model for curzerene concentration is shown in Table 1.5. The linear and square effects of pressure give both significant and nonsignificant effect respectively. For the temperature effects, both linear and quadratic term also expressed significant and nonsignificant. The interaction between pressure and temperature displayed a significant effect within the experimental ranges. 
Table 1.4: The ANOVA for regression model and respective model term for oil yield

\begin{tabular}{|c|c|c|}
\hline Source & $\mathbf{P}<\mathbf{F}$ & Remarks \\
\hline Model & 0.0159 & Significant \\
\hline A-Pressure & 0.0149 & Significant \\
\hline B-Temperature & 0.3558 & Not significant \\
\hline $\mathrm{AB}$ & 0.0177 & Significant \\
\hline $\mathrm{A}^{2}$ & 0.0140 & Significant \\
\hline $\mathrm{B}^{2}$ & 0.3798 & Not significant \\
\hline
\end{tabular}

Table 1.5: The ANOVA for regression model and respective model term for Curzerene concentration

\begin{tabular}{|c|c|c|}
\hline Source & P $<\mathbf{F}$ & Remarks \\
\hline Model & 0.0005 & Significant \\
\hline A-Pressure & 0.0031 & Significant \\
\hline B-Temperature & 0.0006 & Significant \\
\hline $\mathrm{AB}$ & 0.0004 & Significant \\
\hline $\mathrm{A}^{2}$ & 0.3409 & Not significant \\
\hline $\mathrm{B}^{2}$ & 0.1076 & Not significant \\
\hline
\end{tabular}

Figure 1.3 and 1.4 illustrate the interaction between independent variables and responses represented in 3-Dimensional response surface. Based on Figure 1.3, the oil yield increased as the pressure increased at a constant temperature. However, this only happened when it is increased up to the 200 bar for temperature ranges. Note that, above 200 bar, there was a fluctuation in oil yield percentage even though the pressure was high. Meanwhile, at constant pressure, the oil yield increased as the temperature increased. It is obviously shown that high temperature $\left(60^{\circ} \mathrm{C}\right)$ with low pressure (100 bar) did not exhibit a good oil yield and is in contrast with the combination of low temperature $\left(40^{\circ} \mathrm{C}\right)$ and high pressure $(300 \mathrm{~b})$. According to Figure 1.4, the temperature had the important influence on the curzerene concentration. It is showed that the curzerene concentration decreased with the increase of temperature at a constant pressure. The use of high temperature may lead to the degradation of extracts' quality especially heat sensitive materials.

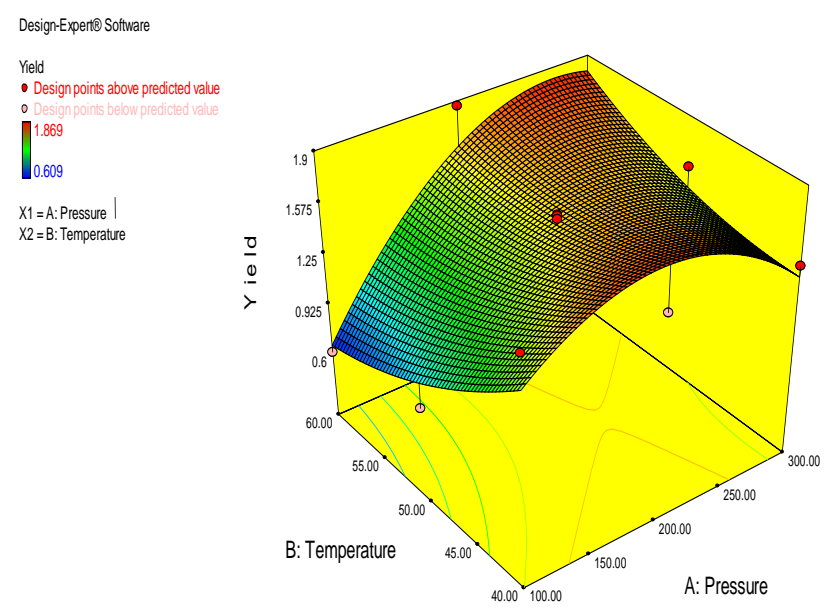

Fig. 1.3: Response surface for oil yield percentage as a function of temperature and pressure
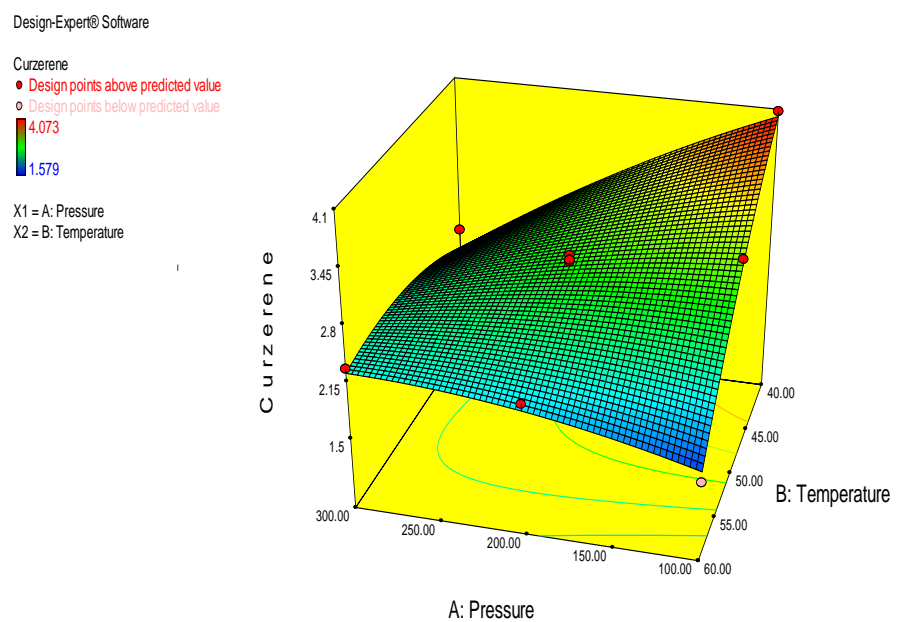

Fig. 1.4: Response surface for curzerene concentration percentage as a function of temperature and pressure

The optimum pressure and temperature were determined based on the high desirability of response. In this study, it is desirable to obtain high oil yield and curzerene concentration within the ranges of pressure and temperature that are cost-effective. In economic perspective, low pressure and temperature consumption reduces the overall operating cost and capital cost. The optimum pressure and temperature in producing highest oil yield and curzerene concentration were 138.65 bar and $40^{\circ} \mathrm{C}$ respectively. The predicted oil yield percentage and curzerene concentration were $1.664 \mathrm{w} / \mathrm{w} \%$ and $3.696 \%$. Technically, these optimum values complied with the values obtained from experiment (100 bar and $40^{\circ} \mathrm{C}$ ) which are $1.654 \mathrm{w} / \mathrm{w} \%$ and $4.073 \%$. The pressure and temperature significantly affected the oil yield and the concentration of oil compounds with $p \leq 0.05$ for both factors. Particularly, the oil yield and curzerene concentration increased as the pressure and temperature increased.

\section{Conclusion}

In summary, the optimisation of SFE of $C$. zedoaria parameters using response surface methodology (RSM) was accomplished in this study. According to the analysis:

1) Curzerene is the major constituent identified in the extracts. A kovats index (KI) has been calculated to confirm the presence of constituent. The highest percentage of curzerene was $4.07 \%$. This major constituent is valuable and unique for bioactive compound in pharmaceutical applications.

2) Supercritical extraction of $C$. zedoaria at 138.65 bar and $40^{\circ} \mathrm{C}$ has been determined by RSM as the optimum conditions. These optimum parameters demonstrated as the best predicted oil yield and curzerene concentration at 1.664 $\mathrm{w} / \mathrm{w} \%$ and $3.696 \%$, respectively.

\section{Acknowledgement}

The authors acknowledge the cooperation with Forest Research Institute Malaysia (FRIM) for technical support and providing information through the project. The authors also would like to thank Universiti Teknologi MARA (UiTM) for funding this study.

\section{References}

[1] Angel, G.R., Nirmala, M., Vimala, B.\& Bala, N. (2014). Essential oil composition fof eight starchy Curcuma species. Industrial Crops and Products, 233-238.

[2] Awasthi, P.K. \& Dixit, S.C. (2009). Chemical composition of Curcuma Longa Leaves and Rhizome Oil from the Plains of Northern India. Journal Young Pharmaceutical 1(4), 312-316. 
[3] Azmir, J., Zaidul, I.S.M, Sharif, K.M., Uddin, M.S., Jahurul, M.H.A, Jinap, S., Hajeb, P. \& Mohamed, A. (2014). Supercritical Carbon Dioxide Extraction of Highly Unsaturated Oil from Phaleria Macrocarpa Seed. Food research International 65, 394-400.

[4] Hong,S.L., Lee, G.S., Syarifah, N.S.A.R., Omar, A.A.H., Khalijah,A. Nurfina,A.N. \& Nurestri,S.A.M. (2014). Essential Oil Content of the Rhizome of Curcuma purpurascens BI. (Temu Tis) and Its Antiproliferative Effect on Selected Human Carcinoma Cell Lines. The Scientific World Journal, pp 7.

[5] Manickam, S. \& Tan. K. W. (2012). Response Surface Methodology, an Effective Strategy in the Optimization of the generation of Curcumin- loaded micelles. Asia -Pacific Journal of Chemical Engineering.

[6] Mau, J.L., Lai, E.Y.C., Nai, P.W., Chien, C.C., Chi, H.C., \& Charng, C.C. (2003). Composition and Antioxidant Activity of the Essential Oil from Curcuma Zedoaria. Food chemistry, pp 583-591.

[7] Ouzzar M.L., Louaer W., Zermane A., Meniai A.H (2015). Comparison of the Performances of Hydrodistillation and Supercritical $\mathrm{CO} 2$ Extraction Processes for Essential Oil Extraction from Rosemary (Romarinus Officinalis L.). Chemical Engineering Transaction, 43, pp 1129-1134.

[8] Paulicci, V. P., Couto, R. O., Teixeira, C. C. C. \& Freitas, L. A. P. (2012). Optimization of the extraction of curcumin from Curcuma Longa rhizomes. Brazillian Journal of Pharmacognosy 23(1), pp. 94-100.

[9] Pharmaceuticals, Cosmetics and Dietry Products. Department of Chemical and Environmental Process Engineering.

[10] Richard,L. \& Kirti,S.P.,Annie, S., (2009). Curcuma zedoaria Rosc (white turmeric): A Review of Its Chemical, Pharmacological and Ethnomedicinal Properties. Journal of Pharmacy and Pharmacology 61, pp 13-21

[11] Rodrigues, V.M., Elisa, M.B.D, Alcilene, R. Osvaldo, C.F., Marcia, O.M \& Angela, A.M. (2002). Determination Of The Solubility Of Extracts From Vegetables Raw Material In Pressurized CO2 : Apseudo Ternary Mixture Formed By Cellulosic Structure +Solute+ Solvent. Journal of supercritical fluid 22, pp.21-36

[12] Siti, H. M. S., zaibunnisa, A. H., Khisdzir, I., Nooraain, H. \& Wan I. W. I. (2015). Optimization of Curcuma Loga L. Rhizome supercritical carbon Dioxide Extraction (SC-CO2) by Response Surface Methodology (RSM). Jurnal Teknologi (Sciences and Engineering) (78:6-6), 87-92.

[13] Shih, J.H., Chang, C.C., Ching, H. T., Chien, C. C., Jeng, L. M., \& Shu, Y. T. (2015). Antioxidants Properties of Extracts from Curcuma Zedoaria Rhizome. Advanced Materials research vols 1120 1121, pp. 928-925.

[14] Zhari,S. (2007). Development of Identification Technique by FTIR-PCA for Supercriticallly Extracted Metabolites from Parkia Speciosa (Hassk) Seeds. Master of Science Degree.

[15] Zhihui,H. (2014). Preparation Process of Zedoary Oil Submicron Emulsion. Patents: CN 103127442. A Retrieved on 17th May 2017 from https://www.google.com/patents/ CN103127442Acl=en. 